\title{
Alex Flemming: corpo, conflito e utopia em Bodybuilders
}

\author{
Alex Flemming: Body, Conflict and Utopia in Bodybuilders \\ Alex Flemming: cuerpo, conflicto y utopía en Bodybuilders
}

Lucas Procópio de Oliveira Tolotti (Universidade de São Paulo, Brasil) *1

https://doi.org/10.22409/poiesis.v21i36.40408

RESUMO: Entre os temas mais presentes no repertório de Alex Flemming, surge o corpo e as questões que o envolvem. A série Bodybuilders, produzida a partir de 1997, situa a temática apresentada em um contexto muito próprio do final do século XX: globalização, novas tecnologias e pós-colonialismo. Como esses temas são articulados nesta série de obras? Qual o corpo que nela se apresenta e de que maneira a série se envolve na própria trajetória pessoal do artista? Por meio da análise de um determinado conjunto desses trabalhos, o artigo perquire os diversos corpos que se estendem plasticamente nas telas, situando-os junto às questões sociopolíticas do final do século XX e início do século XXI. Para isso, além de textos de críticos de arte que versam sobre o artista, as reflexões serão pautadas por Michel Foucault e Homi K. Bhabha.

PALAVRAS-CHAVE: Alex Flemming; corpo; Bodybuilders; conflito; utopia

* Lucas Procópio de Oliveira Tolotti é mestre e doutorando em Estética e História da Arte pelo Programa de Pós-Graduação em Estética e História da Arte da Universidade de São Paulo (PGEHA/USP). E-mail: lucas.tolotti@usp.br. Orcid: https://orcid.org/0000-0003-2473-0852 
ABSTRACT: Amongst the present themes in the repertoire of Alex Flemming, the body and the issues that surround it arise. Looking at the Bodybuilders series, produced from 1997 onwards, this theme is presented in a very specific context of the late twentieth century: globalization, new technologies and postcolonialism. How are these themes articulated in this series of works? Which body is presented in it and how does the series become involved in the artist's own personal trajectory? Through the analysis of a certain set of these works, the article examines the various bodies that extend plastically on canvas, placing them accordingly to the sociopolitical issues of the late twentieth and early twenty-first centuries. Besides texts by art critics about the artist, Michel Foucault and Homi K. Bhabha will guide the reflections.

KEYWORDS: Alex Flemming; body; Bodybuilders; conflict; utopia

RESUMEN: Entre los temas más presentes en el repertorio de Alex Flemming se encuentran el cuerpo y los problemas que lo rodean. La serie Bodybuilders, producida desde 1997, sitúa el tema presentado en un contexto muy específico de finales del siglo XX: la globalización, las nuevas tecnologías y el poscolonialismo. ¿Cómo se articulan estos temas en esta serie de obras? ¿Qué cuerpo se presenta y cómo se involucra la serie en la trayectoria personal del artista? A través del análisis de determinado conjunto de estas obras, el artículo examina los diversos cuerpos que se extienden plásticamente en los lienzos, colocándolos cerca de los problemas sociopolíticos de finales del siglo XX y principios del XXI. Para esto, además de los textos de críticos de arte sobre el artista, las reflexiones serán guiadas por Michel Foucault y Homi K. Bhabha.

PALABRAS CLAVE: Alex Flemming; cuerpo; Bodybuilders; conflicto; utopía

Recebido: 15/3/2020; Aprovado: 8/5/2020; Publicado: 1/7/2020

Citação recomendada:

TOLOTTI, Lucas Procópio de Oliveira. Alex Flemming: corpo, conflito e utopia em Bodybuilders. Revista Poiésis, Niterói, v. 21, n. 36, p. 285-306, jul./dez. 2020.

[https://doi.org/10.22409/poiesis.v21i36.40408]

(cc) BY-NC-ND Este documento é distribuído nos termos da licença Creative Commons Atribuição-NãoComercial 4.0 Internacional (CC-BY-NC) (c) 2020 Lucas Procópio O. Tolotti

Lucas Procópio de Oliveira Tolotti, Alex Flemming: corpo, conflito e utopia em Bodybuilders. 


\section{Alex Flemming: corpo, conflito e utopia em Bodybuilders}

\section{Uma trajetória artística do corpo}

Alex Flemming ${ }^{2}$, quando chega à produção de Bodybuilders a partir de 1997, em plena maturidade artística, faz uso da autorreferência. O corpo e a fotografia, o político e o estético de outros momentos poéticos se unem, criando um espaço em que são discutidas as relações de vida e erotismo, morte e belicismo. Em uma carta endereçada a Ana Mae Barbosa, Flemming descreve a obra:

Trata-se de novas fotografias que realizei com auxílio de computadores, onde retratei corpos jovens e esbeltos em cima dos quais desenhei com computador mapas de áreas de conflitos e guer- ras. Ora, a maioria (senão a quase totalidade) das áreas beligerantes no mundo do século XX é resultado das partilhas coloniais das grandes potências dos séculos XVIII e XIX. Do Oriente Médio até a região de Chiapas, no México, passando pela África e mesmo pelos Bálcãs, o que vemos são consequências de políticas coloniais (europeias, soviéticas, turcas) sobre áreas de população com tradição distinta das de seus senhores. Fiz gigantescas ampliações sobre plástico (2,10 x 1,60 m), montadas sobre bastidores como se fossem telas, em cima das quais escrevi textos do Antigo Testamento que já falam de guerras e perseguições, que vão desde a diferença de etnias, a religiões ou posse de terra e seus frutos. (BARBOSA, 2002, p. 13) 
Bodybuilders remete à espiral presente em Flemming de vida/corpo/morte ${ }^{3}$, sendo a continuação de seu percurso poético traçado sobre essas voltas. Além da espiral temática, as técnicas encontradas pelo artista ressoam como ecos de trabalhos passados que são incorporados e atualizados à voz presente de sua produção. A fotografia, que está presente desde o começo de sua trajetória, é reproduzida digitalmente em pvc, aproveitando-se da tecnologia de impressão da época ${ }^{4}$. São fotografados corpos musculosos em mínimos trajes de banhos - alguns nus - e sobre conflitos geopolíticos ao redor do mundo, como os movimentos entre Israel e Palestina, Índia e Paquistão, Geórgia e Rússia, entre outros que, segundo o artista, são resultados de políticas coloniais. Importante situar então o lugar da crítica e das perspectivas pós-coloniais que se fazem presentes na tessitura da obra:

\author{
A crítica pós-colonial é testemunha das forças de- \\ siguais e irregulares de representação cultural \\ envolvidas na competição pela autoridade políti- \\ ca e social dentro da ordem do mundo moderno. \\ As perspectivas pós-coloniais emergem do tes- \\ temunho colonial dos países do Terceiro Mundo e
}

dos discursos das "minorias" dentro das divisões geopolíticas de Leste e Oeste, Norte e Sul. Elas intervêm naqueles discursos ideológicos da modernidade que tentam dar uma "normalidade" hegemônica ao desenvolvimento irregular e às histórias diferenciadas de nações, raças, comunidades, povos. (BHABHA, 2019, p. 276)

Completa Barbosa (2002, p. 18): "o póscolonialismo, como o vejo na obra de Flemming, não é uma reflexão sobre a identidade em agonia, mas uma reestruturação do poder de autodefinição, apesar dos conflitos externos ao sujeito e ao seu ordenamento vital". A reestruturação tem lugar na própria linguagem, visto que, em tradução literal, bodybuilder é o construtor do corpo.

Ao escolher a figura do bodybuilder para discutir o corpo no final do século $X X$, Flemming não descarta as relações que outros corpos tiveram em sua obra, pelo contrário: no conjunto da série, estão relacionadas as mais diversas manifestações corpóreas que fazem parte de sua produção poética desde 1978. As séries Natureza-morta (1978), Eros Expectante (1980) e Atletas (1998) se configuram como fases-chave na exploração deste tema por 
Flemming. Em Natureza-morta, conjunto de fotogravuras realizadas no período da ditadura militar brasileira, corpos são fotografados simulando práticas de tortura. Na série seguinte, Eros Expectante, do suplício nasce a espera, e masculino e feminino são colocados nus prestes a receber um o corpo do outro. Por fim, em Atletas, o corpo musculoso do esportista é contrastado com a beleza em ruínas da escultura grega que, durante a história, foi peça importante para a definição e manutenção de padrões estéticos. Nas três produções, é percebido o véu da disciplina em um sentido foucaultiano: o governo ditatorial, o sexo, o tempo e os exercícios desempenham pressões reguladoras, moldando o corpo e apresentando-o conforme seus desígnios. Não apenas a disciplina, mas também a biopolítica e seu conceito de "direito de morte e poder sobre a vida" (FOUCAULT, 2015, p. 145) é corporificada pelos bodybuilders. Então, de sua emergência, vê-se um corpo também disciplinado pelas questões políticas e identitárias que permeiam o final dos anos 1990.

As forças às quais está sujeito o corpo agora preconizado por Flemming em Bodybuilders são diversas: não se esquece do próprio erotismo, visto que os modelos fotografados pelo artista estão plenamente vigorosos (físico e sexual), exsudando sensualidade - mas todas essas características são ameaçadas pela guerra. Como articular, pois, essa rede de forças que atinge e, ao mesmo tempo, emerge do corpo na série em questão?

\section{$O$ corpo do mundo no final do século $X X$}

As metáforas corpóreas articuladas em Flemming são ambivalentes: o corpo se configura como uma couraça, uma proteção (BARBOSA, 2002, p. 13), bem como é uma arma, um dispositivo que mata. (LAUDANNA, 2016, p. 11) Mais ainda, o artista chama atenção à questão da jovialidade do corpo que é mandado para o campo de batalha, sendo assim privado de suas potências pubescentes.

A obra NATO Seeblockade (2001, Fig. 1) apresenta a fotografia de um modelo, sendo o mapa da guerra da Bósnia sobre ele inserido digitalmente. O conflito entre a então Iugoslávia, Bósnia e Croácia se estende de 1992 a 1995, resultado do fim 


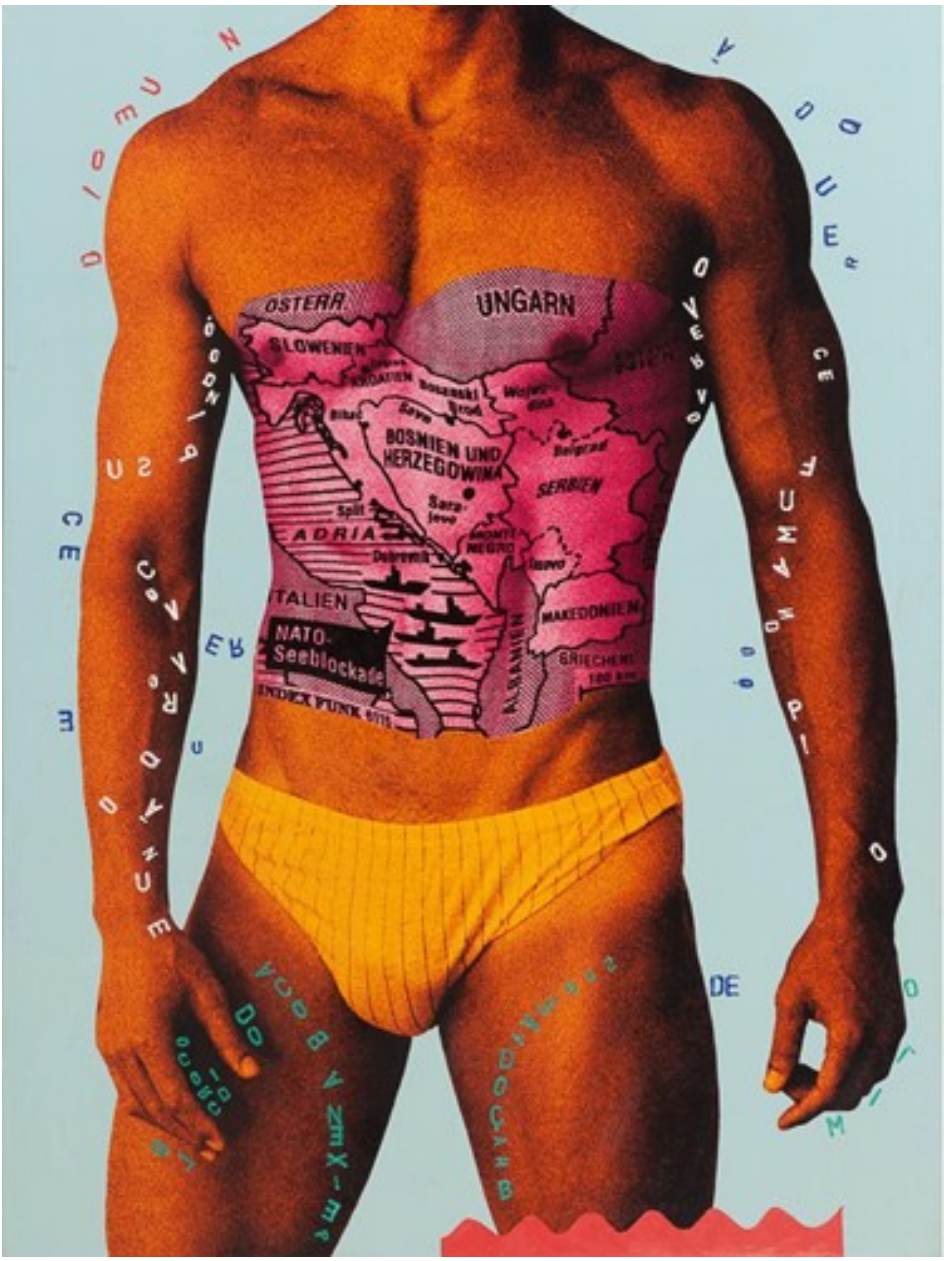

Fig. 1 - Alex Flemming, NATO Seeblockade, 2001.

tinta acrílica sobre fotografia sobre pvc, $203 \times 155 \mathrm{~cm}$

(Fonte: Imagem cedida por Henrique Luz) 
da Guerra Fria e de levantes nacionalistas e separatistas. A conflagração contou com a intervenção da Organização do Tratado do Atlântico Norte (OTAN) para estabelecer e manter a paz.

Além do esquema cartográfico, Flemming espalha pelo trabalho uma série de letras que, se desconexas à primeira vista, ao serem lidas com atenção revelam trechos da música Bandeira, do cantor e compositor Zeca Baleiro:

\section{Eu não quero ver você cuspindo ódio Eu não quero ver você fumando ópio$$
\text { [...] }
$$ \\ Peixe na boca do crocodilo \\ Braço da Vênus de Milo acenando tchau (BALEIRO, 1997)}

Todas essas informações criam uma narrativa visual e permitem uma relação entre si, mediadas pelo corpo. As palavras envolvem o soldado-bodybuilder, levando o recado do artista àqueles que lutam: "eu não quero ver você cuspindo ódio". O braço da Vênus de Milo - referência grega que remete à inexorabilidade do tempo tratada em Atletas - acena tchau, despede-se do corpo que dura pouco e, talvez, é mutilado da mesma forma que mutila, perdendo um braço assim como a própria obra de arte referida por Zeca Baleiro.

Em uma variação de NATO Seeblockade, a música de Zeca Baleiro é substituída por Te Ver, da banda Skank:

\section{Te ver e não te querer \\ É improvável, é impossível \\ Te ter e ter que esquecer \\ É insuportável, é dor incrível (ROSA; ZANETTI; AMARAL, 1994)}

O que envolve o corpo do Bodybuilder agora não é mais uma reflexão sobre as ações temíveis que podem ser realizadas pelo corpo presente na tela. Usada por Flemming, a letra de Te Ver revela o desejo que o erotismo do corpo masculino musculoso e vigoroso produz. Poder possuir o dono desse corpo e logo em seguida ter de deixá-lo, lançá-lo à guerra, é pesaroso. Como afirma Canton (2002, p. 53), "Flemming retrata corpos jovens, com a musculatura rígida, lançando sobre eles um olhar complexo, ora deslumbrado e atraído, ora penalizado e consciente da efemeridade do corpo e da vida". 
Ao transportar o mapa para o bodybuilder, Flemming permite a reflexão do corpo como lugar. Não só a representação de uma região que está inserida no músculo, mas, ele (o músculo) com sua pele e seus ligamentos, é um lugar. Afirmam Villaça e Goés (2014, p. 85):

Na sequência da aceleração tecnológica, grande vitoriosa na débâcle das utopias que caracterizaram o pós-guerra, o espaço e seu imaginário de concretude e realidade são desrealizados seja no que diz respeito ao nacional, desconstruídos no processo de globalização; sejam em outros tipos dependentes da determinação de um território.

[...] A velocidade das transformações contemporâneas faz com que cada vez mais o espaço não seja visto como algo exterior ao sujeito, seu cenário, coisa extensa, passando a elemento constitutivo de sua estruturação.

Assim sendo, o bodybuilder de Flemming não apenas batalha nos campos inscritos pelos mapas, mas é afetado pelas regiões, constroe-se de acordo com os conflitos e para eles. Então, "o corpo é utilizado como metáfora da sociedade como um todo. [...] Em tempos de crise social, quando as fronteiras nacionais e as identidades são ameaçadas, é comum haver preocupação com a manutenção dos limites corporais e a pureza dos corpos". (VILLAÇA; GOÉS, 2014, p. 106)

Essa ideia se comunica com a biopolítica e a disciplina de Foucault. Há a gerência da vida - da saúde, do comportamento, da alimentação - que incide diretamente sobre o espaço que é o corpo: países em guerra produzem corpos que atendem às demandas necessárias. Mais ainda, perscrutando o caminho realizado pelos soldados-bodybuilders de Flemming, o que se configura soberanamente incide de maneira mais contumaz a esse indivíduo: é a disciplina dos quartéis e do exército, dos regimes e regulações internas. A sujeição aparece também em Turquia (2000), onde o mapa inscrito no abdômen masculino agora é do conflito turco-curdo. Entre reivindicações nacionalistas e integrações forçadas, Flemming chama atenção mais uma vez para o corpo do indivíduo que luta - não importando qual o lado - evidenciando os músculos que são aproveitados para matar, quando na verdade deveriam ser utilizados para viver a juventude. Contornando os braços do modelo, uma frase da música Se Você Pensa, de Roberto Car- 
los: "Seu orgulho não vale nada!" (CARLOS; CARLOS, 1968)

O artista também coloca elementos nãoverbais, como é o caso dos círculos coloridos, aumentando a densidade plástica da obra e reforçando sua estética pós-pop. Assim, imagens de meios de comunicação (os mapas) e elementos da cultura de massa (letra de música) aparecem como modo de chamar atenção para as contradições da realidade atual (a guerra). Porém, o centro de toda a reflexão não deixa de ser o corpo. O conflito nele incide, é ele que mata ou se protege; vive uma vida completa ou morre lutando por um ideal que pode não ser o seu. Plasticamente, reafirma-se também sua importância, já que, por mais que mudem as cores do fundo ou as palavras e desenhos que o envolvem, é ele que continua estoicamente presente no centro da composição, ampliado pela fotografia em pvc que evidencia sua pele e o grão da imagem.

Misticismo e religião têm presença marcante na obra de Flemming e, em Bodybuilders, determinadas obras contêm trechos retirados da Bíblia, como é o caso de Georgien (2001, Fig. 2):
Moisés, porém, disse ao povo: Não temais; estai quietos, e vede o livramento do Senhor, que hoje vos fará; porque os egípcios, que hoje vistes, nunca mais vereis para sempre. (BÍBLIA, 1995)

A passagem do livro do Êxodo reitera a ideia da demarcação de um território e a fuga de um povo - no caso, israelita - do Egito para a terra prometida. Flemming mostra que as questões nacionais e identitárias percorrem a história, sendo interessante notar a escolha do referido versículo da Bíblia - que não é colocado na obra de Bodybuilders dedicada às questões entre Israel e Palestina, mas é deslocada espacialmente, chegando à região do Cáucaso, nas questões separatistas na Geórgia -, promovendo uma continuidade que abarca todo o conjunto de obras, universalizando a história do povo judeu e transformandoa em metáfora da busca pela identidade nacional que é a origem dos conflitos explicitados no mapa.

Flemming altera digitalmente a fotografia em Georgien e o sombreado que distingue o corpo é apresentado em tons de verdes antinaturais, provocando um efeito que extrapola o humano - dialogando com a imagem do corpo que aparece no final do 


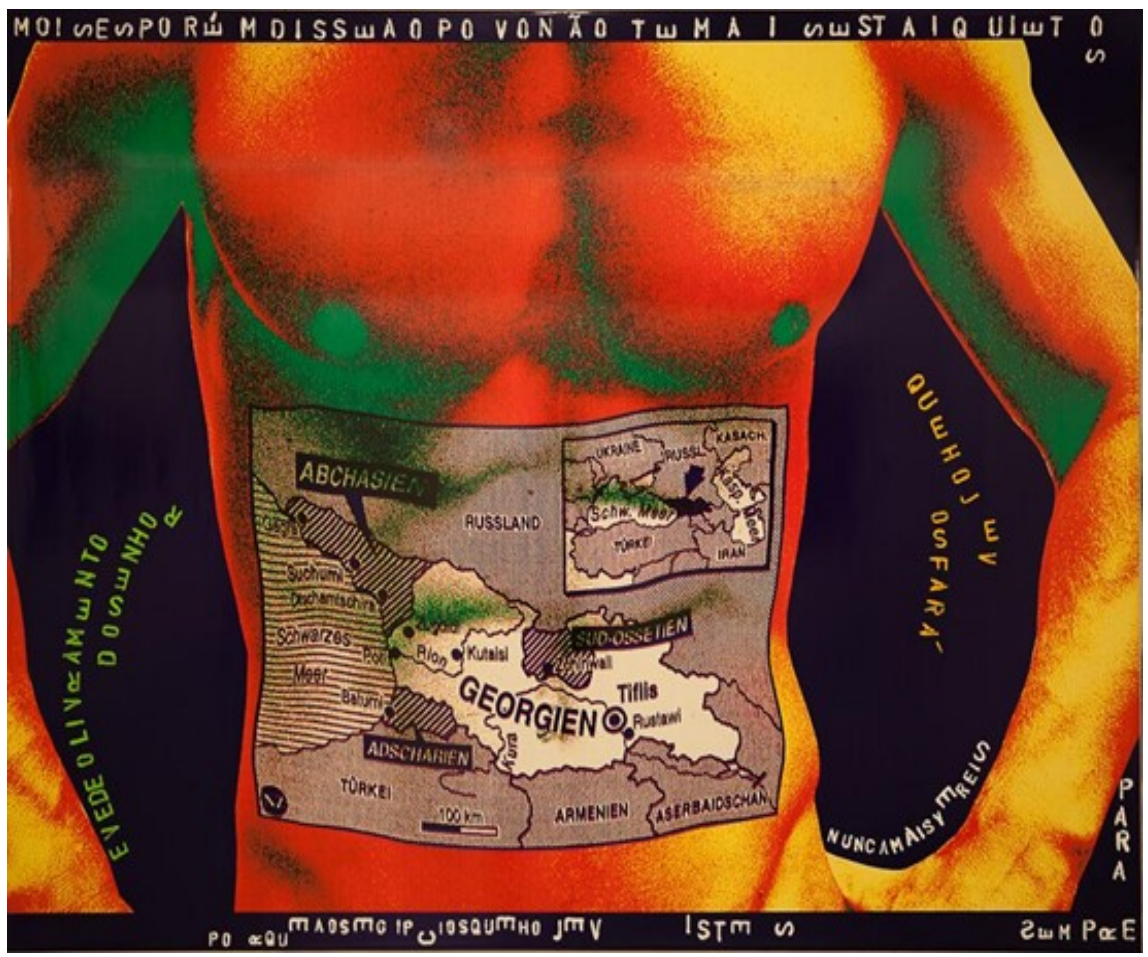

Fig. 2 - Alex Flemming, Georgien, 2001.

tinta acrílica sobre fotografia sobre pvc, 154 × $202 \mathrm{~cm}$

(Fonte: Imagem cedida por Henrique Luz)

Lucas Procópio de Oliveira Tolotti, Alex Flemming: corpo, conflito e utopia em Bodybuilders. 
século XX e começo do século XXI, que não se inscreve apenas no domínio do real, expandindo-se para o virtual. Assim, ao embate homem/máquina se instauram novas maneiras de existência e experiências únicas proporcionadas pelo ciberespaço. Esse alargamento de fronteiras estabelece "uma indeterminação de limites entre natureza e cultura, real e irreal com figurações inverossímeis e grotescas". (VILLAÇA; GOÉS, 2004, p. 107)

Os bodybuilders de Flemming apresentam reconfigurações virtuais estéticas - cores não-humanas na pele - que implicam sua existência não apenas, então, como jovens enviados à guerra, mas como máquinas - disciplinadas - prontas a entrar em combate, como se verifica na obra Somália (2003, Fig. 3), que exibe a guerra civil naquele país. Além do mapa e do corpo colorido, Flemming emprega novamente palavras em sua composição, dessa vez com um exemplo da literatura portuguesa contemporânea, a frase do livro Um estranho em Goa, do autor português José Eduardo Agualusa: "[...] ordenou que o corpo [do Santo] fosse retirado da basílica e exposto em praça pública". (2010)
Somália comprova que as decisões estéticas de Flemming a respeito da série Bodybuilders de fato se estendem e compreendem todo seu conjunto. Afinal, o conflito não se encerra no país africano: outros indícios geográficos são dados, como Goa e sua relação colonial com Portugal. A coIonização e a relação da cultura europeia com outras são expressas com força em Bodybuilders e se acentua nesta obra. Junto às questões geográficas e culturais, o corpo é referido no texto imiscuído na religião. Um corpo santificado e morto exposto contrasta com aquele do soldado, musculoso, azul e verde - o oposto da santidade, seja por sua forma, cor, vivacidade ou ações.

O corpo azul se repete na obra Índia $x$ Paquistão (2001, Fig. 4), dessa vez representado de costas: posição indefensável na guerra, deixando-o vulnerável. Essa fragilidade, esse dar as costas para o conflito libera o corpo para o prazer, a música, o carnaval, de acordo com a letra da marchinha tradicional que envolve os glúteos estampados com a disputa do território da Caxemira pela Índia e Paquistão, ao mesmo tempo que caminha entre as pernas: 


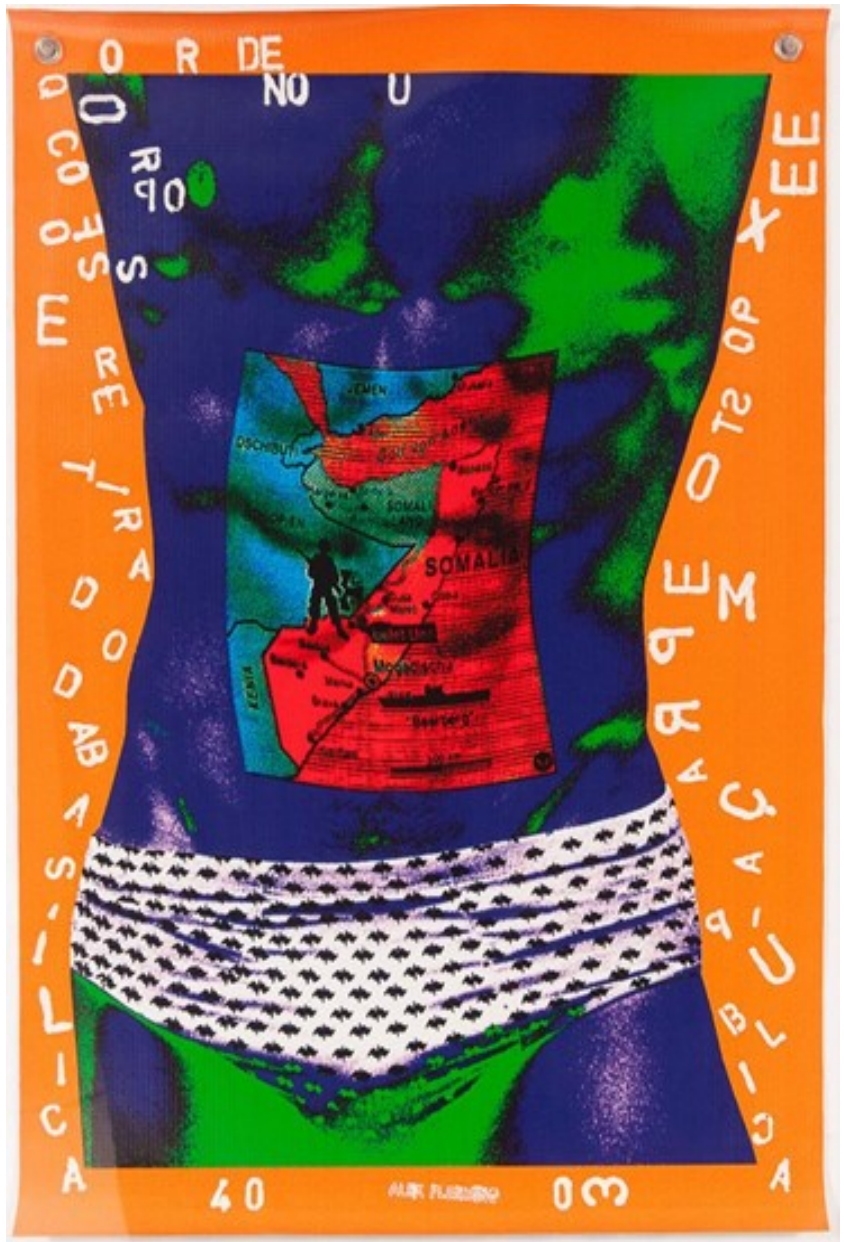

Fig. 3 - Alex Flemming, Somália, 2003.

tinta acrílica sobre fotografia sobre pvc, $78 \times 54 \mathrm{~cm}$

(Fonte: Imaqem cedida por Henrique Luz)

Lucas Procópio de Oliveira Tolotti, Alex Flemming: corpo, conflito e utopia em Bodybuilders. 


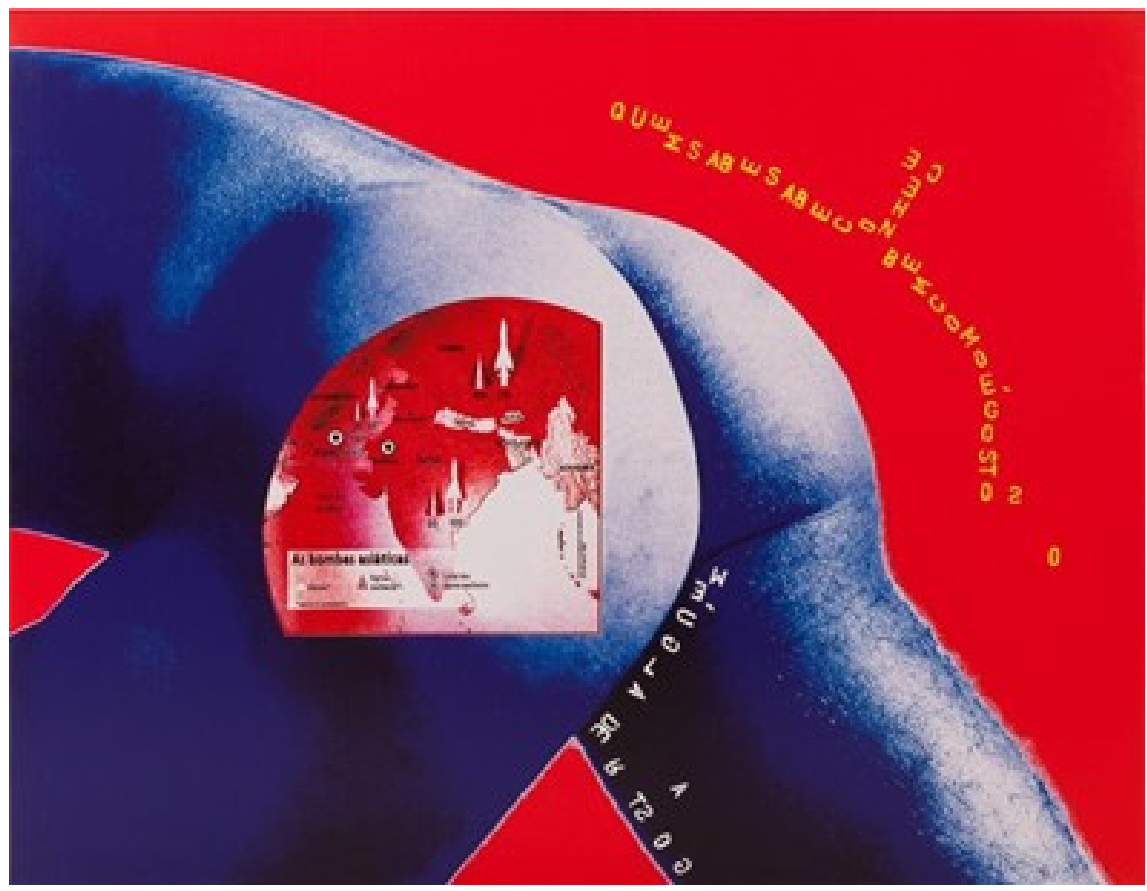

Fig. 4 - Alex Flemming, Índia x Paquistão, 2001.

tinta acrílica sobre fotografia sobre pvc, $155 \times 203 \mathrm{~cm}$

(Fonte: Imagem cedida por Henrique Luz)

Revista Poiésis, Niterói, v. 21, n. 36, p. 285-306, jul./dez. 2020. (https://doi.org/10.22409/poiesis.v21i36.40408) 
Quem sabe, sabe

Conhece bem

Como é gostoso

Gostar de alguém (SANDOVAL; CARVALHINHO,

1956)

Em Israel (2001, Fig. 5) e sua variação, voltam a força e a austeridade características dos soldados-bodybuilders: a cor verde reforça o ideal pós-humano que a prática contém. O grão da fotografia é marcante, característica que a técnica de impressão em pvc ajuda a ressaltar, conferindo uma materialidade visual de impacto. Nessas obras, Jerusalém é o umbigo do mundo (FLEMMING, 2018, p. 64). Entre a fé e a guerra, Jerusalém faz parte de um universo onde planetas orbitam ao seu redor, e os desenhos em tinta acrílica sugerem corpos celestiais que convergem para a região do Oriente Médio. Essas imagens, em obra posterior, são substituídas por trechos da música Tubi Tupi, de Lenine:

Eu sou feito de restos de estrelas

Como o corvo, o carvalho e o carvão

As sementes nasceram das cinzas

De uma delas depois da explosão

Sou o índio da estrela veloz e brilhante
Que éforte como o jabuti

0 de antes de agora em diante

E as distantes galáxias daqui (LENINE; RENNÓ, 1999)

A música integra o espaço astronômico à origem brasileira indígena e, assim, Flemming a engloba no contexto cosmológico do corpo e da guerra. Em Jerusalém, o corpo é a própria terra prometida ${ }^{5}$, o espaço onde convergem os poderes, as disciplinas e os prazeres. Como se corroborado pela música, ele é forte e se encontra pronto para a luta, da mesma maneira que Israel com seu arsenal militar.

\section{Utopia da guerra, utopia do corpo}

Vida e morte, guerra e repressão acontecem no corpo. Por que Flemming, ao denunciar situações alarmantes, coloca o soldado como bodybuilder? Qual a relação entre guerra e a prática do bodybuilding? A definição do termo bodybuilding e sua tradução encontram alguns percalços (COURTINE, 2005, p. 106). A tradução pelo seu equivalente em português, fisiculturismo ou halterofilismo, não dá conta da complexidade que a palavra em inglês car- 


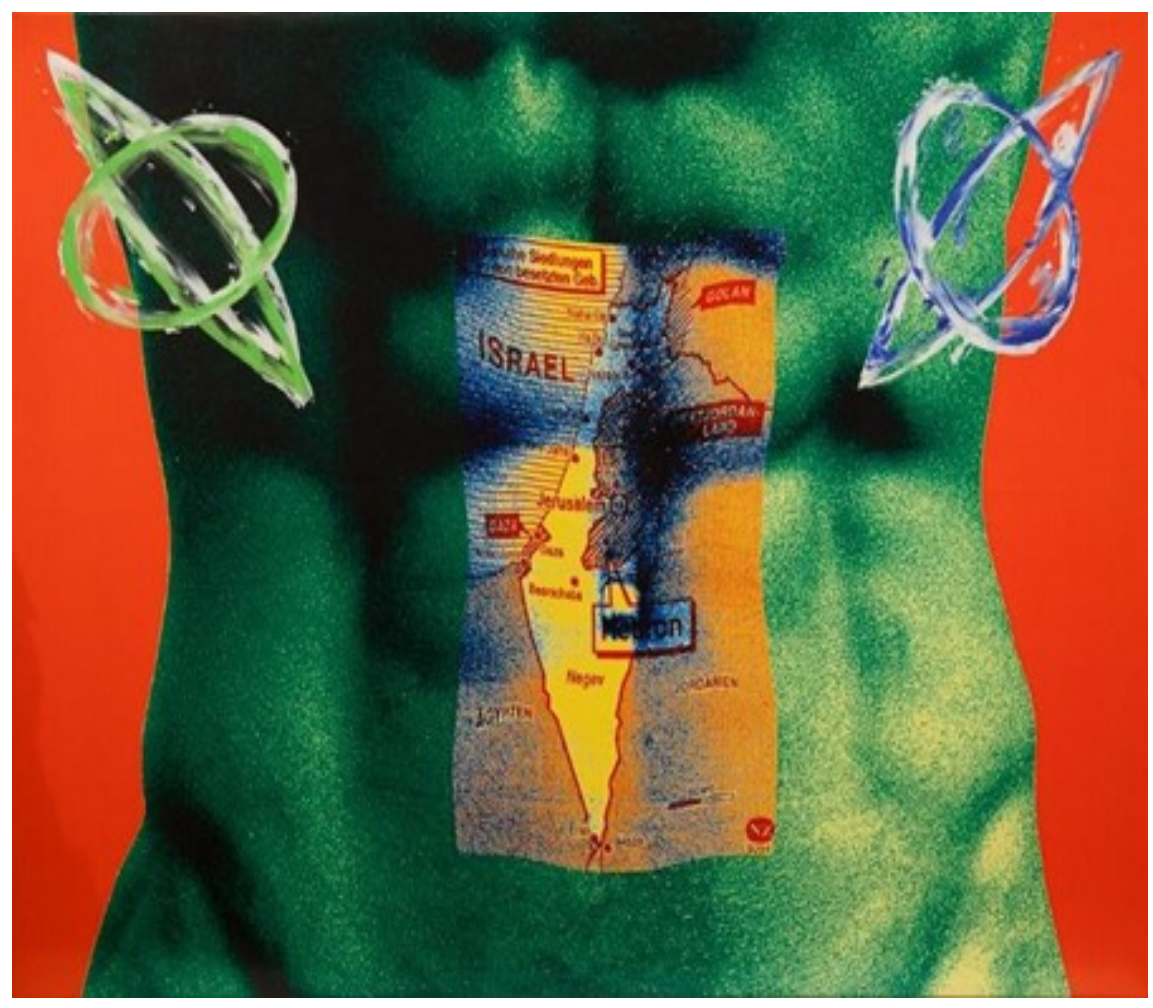

Fig. 5 - Alex Flemming, Israel, 2001.

tinta acrílica sobre fotografia sobre pvc, $155 \times 203 \mathrm{~cm}$

(Fonte: Imaqem cedida por Henrique Luz) 
rega, uma vez que assume o significado de construção do corpo. A ideia da construção apresenta um papel importante nessa prática e extrapola os limites de cultivo da forma ou da ideia de que a expressão está arraigada ao levantamento de peso.

Ao nomear a série, Flemming implica que não se trata de corpos franzinos e despreparados. A palavra do título carrega seu sentido como o próprio músculo do indivíduo que o constrói. Essa construção exige disciplina e comprometimento, qualidades valorizadas nos quartéis. Porém, como observado acima, o bodybuilding sofre alterações ao longo do século $X X$ junto com os novos meios de comunicação e outros paradigmas corporais.

Gatti (2011, p. 229) propõe uma divisão do corpo dentro do contexto do bodybuilding no século XX: o corpo Sandow e o corpo Arnold. O primeiro remonta à figura do atleta Eugene Sandow, que recupera o ideal greco-romano de uma construção de si, apregoada na realidade das proporções e até mesmo em uma sensibilidade estética que permita adentrar nos terrenos do homoerotismo. Já o segundo, de Arnold
Schwarzenegger, corresponde ao grotesco, ao inatingível: à brutalidade conquistada quimicamente.

Qual corpo, então, Flemming apresenta? Os combatentes das obras em questão sem dúvida apresentam tórax, braços e pernas hipertrofiados, mas carregam um ideal corpóreo mais próximo dos bodybuilders da primeira metade do século XX. A superação do humano, que em Schwarzenegger se manifesta nos músculos quase desfigurados, é resolvida plasticamente pelo artista nas cores dos corpos em tela. O cyborg de Flemming possui beleza e destreza gregas, ainda que performe barbaridades na arena bélica. Além disso, o que encena o ponto primordial do corpo é sua potência de vida que, ao mesmo tempo, é sua finitude - a ambivalência corporal (BERNARD, 2016, p. 12). Os bodybuilders são vigorosos, seus corpos estão Ionge da decrepitude, o exercício de suas funções se encontra no mais alto patamar, mas uma bala disparada, uma mina ou uma bomba podem destruí-los e mitigálos. A couraça (BARBOSA, 2002, p. 13) de músculos funciona de fato como proteção, uma maneira de evitar ou retardar a morte iminente. 
O corpo do bodybuilder é um corpo utópico, conforme definição de Foucault em artigo homônimo (2013, p. 8). Os soldados batalham querendo conquistar uma utopia baseada na soberania. O próprio corpo humano é "o ator principal de todas as utopias", (FOUCAULT, 2013, p. 12) Continua:

A utopia é um lugar fora de todos os lugares, mas um lugar onde eu teria um corpo sem corpo, um corpo que seria belo, límpido, transparente, luminoso, veloz, colossal na sua potência, infinito na sua duração, solto, invisível, protegido, sempre transfigurado: pode bem ser que a utopia primeira, a mais inextirpável no coração dos homens, consista primeiramente na utopia de um corpo incorporal. (FOUCAULT, 2013, p. 8)

Foucault apresenta a utopia do corpo incorporal para negar a ambivalência da finitude. Incorporal enquanto dor, mácula, mas totalmente materializado em suas potências de vida, da mesma forma que o bodybuilder se utiliza dos músculos de maneira a exacerbar sua vitalidade. É na ênfase dos atributos físicos em Bodybuilders que ocorre a transformação dos modelos em torsos análogos aos gregos sem rostos (BARBOSA, 2002, p. 13), criando uma ambígua identidade. O anonimato dos bodybuilders sugere a perda da humanidade característica da guerra, no qual vivos e mortos viram estatísticas que aparecem depois em jornais e mapas. Esta utopia se derrama em fronteiras, que são tanto as políticas (denotadas pelos mapas), quanto as do corpo (em sua capacidade utópica) e as temporais (nos limites do século $X X$ ). A articulação permite que Flemming parta da construção de si preconizada pelo bodybuilder para desvelar a elaboração do corpo contemporâneo que é, simultaneamente, tecnológico, cyborg, polivalente, inscrito em biopolíticas, arraigado na cultura, criador e ator de utopias. Corpo, política e erotismo se atravessam no vértice do século $X X$ e Alex Flemming ressalta esses movimentos em sua obra. Foucault, no final de seu artigo sobre o corpo utópico, escreve:

Meu corpo, está, de fato, sempre em outro lugar, ligado a todos os outros lugares do mundo e, na verdade, está em outro lugar que não o mundo. Pois, é em torno dele que as coisas estão dispostas, é em relação a ele - e em relação a ele como em relação a um soberano - que há um acima, um abaixo, uma direita, uma esquerda, um diante, um atrás, um próximo, um longínquo. 0 corpo 
é o ponto zero do mundo, lá onde os caminhos e os espaços se cruzam, o corpo está em parte alguma: ele está no coração do mundo, este pequeno fulcro utópico, a partir do qual eu sonho, falo, avanço, imagino, percebo as coisas em seu lugar e também as nego pelo poder indefinido das utopias que imagino. (FOUCAULT, 2013, p. 14 , grifo do autor)

Esta ubiquidade, este ponto zero, especialmente nas zonas de conflito póscoloniais em questão, remetem ao pedagógico e ao performativo de Bhabha (2019, p. 237) na construção de uma nação. A formação de um povo - consequentemente de seu(s) corpo(s) - consiste na assimilação de seu passado, em uma pedagogia histórica, mas também atua nos novos processos de significação das identidades, visto que são sujeitos performáticos de narrativas a serem construídas.

A figura do atleta - mais especificamente, a do bodybuilder - retomada na série $B O-$ dybuilders revela os passos da trajetória de Flemming e sua visão do corpo dentro dessa pedagogia/performatividade. A pessoa do artista se confunde com as referências históricas e os conflitos trazidos nos mapas impressos nos abdomens ou nas costas dos modelos fotografados. Suas origens, sexualidade, nacionalidade e moradia atual encontram eco nas guerras e conflitos espalhados pelo mundo, contribuindo para a criação de uma narrativa que circula campos autobiográficos, não os encerrando em particularidades, mas permitindo que ele esteja integrado às mais variadas questões contemporâneas, pois as sente, as vivencia.

$\mathrm{Na}$ obra Israel, vê-se claramente como são construídas as relações pessoais junto ao contexto internacional. A própria escolha de homens seminus e musculosos revela preferências, não é arbitrária. O corpo masculino é importante, é erótico, é fonte de alegria e de tristeza, prazer e dor. Quantos caminhos não são percorridos entre o tórax e o abdômen, as pernas, as coxas, os glúteos e os braços? As palavras que tocam ou circundam a pele do soldado têm, em sua pressuposta aleatoriedade, a mão do artista que as articula preciosamente em uma dança estética, que é completada pelas letras e frases que não se furtam também da questão política. Ao embaralhar tantas referências populares, eruditas e religiosas, Flemming permite a visualidade do "nonsense colo- 
nial" (BHABHA, 2019, p. 205), em suas múltiplas referências, abstrações e vivências:

\section{A obra da palavra interfere na questão da assimi- lação transparente de significados transculturais em um signo unitário de cultura "humana". No intervalo da cultura, no ponto de sua articulação da identidade ou da perceptibilidade, vem a questão da significação. Esta não é apenas uma questão de linguagem; é a questão da represen- tação da diferença pela cultura [...]. 0 que será da identidade cultural, da habilidade de pôr a pala- vra certa no lugar certo no momento certo, quando ela atravessa o não senso colonial? (BHABHA, 2019, p. 206)}

Bodybuilders encontra-se hoje de maneira equidistante do começo da produção do artista e seu momento atual. Como sua produção ocorre de maneira espiralada, os temas que permeiam essa série são ressignificados e retomados por Flemming mas ela continua sendo um forte emblema de seu tempo, constituindo um amplo cenário para os debates provenientes do final do século XX e limiares do século XXI, com consequências duradouras. Os caminhos do corpo ao longo da história hoje se convergem na mesma intensidade em que divergem, provocando rupturas para, logo em seguida, produzirem prolongamentos e, dessas construções, novas possibilidades. Como aponta Bhabha (2019, p. 25, grifo do autor): "a fronteira se torna o lugar a partir do qual algo começa a se fazer presente". Bodybuilders atravessa corpos, guerras, campos autobiográficos e pós-colonialidades, onde a leitura da Bíblia é feita em uma festa de carnaval e, ao lado, morrem jovens, democracias e identidades. Resta, então, perquirir novas forças que irão surgir, inevitavelmente, deste corpo que criará uma nova utopia. 


\section{Notas}

${ }^{1} 0$ presente artigo é um extrato da dissertação de mestrado do autor, orientada pela Professora Doutora Elza Ajzenberg, apresentando novas relações, fontes e considerações. Disponível em https: //teses.usp.br/ teses/disponiveis/93/93131/tde-16102019-164230 /publico/2019_LucasTolotti_VOrig.pdf. Acesso em 13/1/2020.

${ }^{2}$ Alex Flemming (1954), artista brasileiro que hoje divide seu tempo entre São Paulo e Berlim, desde o final da década de 1970 apresenta uma produção que se destaca pelo uso de variadas técnicas e meios. Suas obras trazem, dentre outros temas, a referência ao corpo, colocando-o em diálogo com a história da arte, a política e o erotismo. No início de sua trajetória, a gravura e a fotografia eram predominantes. Um dos motivos é o contato direto com artistas em seus ateliês, principalmente Cristiano Mascaro (1944) e Regina Silveira (1939). Em 1981, participou da XVI Bienal Internacional de São Paulo, no segmento Arte Postal, e quando foi para Nova York por intermédio da bolsa Fulbright, lá permanecendo até 1983. Voltando ao Brasil, participou da XVII Bienal Internacional de São Paulo, dessa vez no segmento Arte e Videotexto. A partir da metade da década de 1980, voltou-se para a pintura e a potência das cores, utilizando a técnica de máscaras (técnica similar ao estêncil) para produzir séries como Múmias (1988), Cabeças (1989), Alturas (1989), Atletas (1989) e Traqueotomia (1990). Conforme a década de 1990 avançava, investigando os meios tradicionais da arte, Flemming utilizava móveis, roupas, objetos e até carcaça de animais como suporte para a pintura. É o momento em que o artista se fixa definitivamente em Berlim. Em 1997, inicia a série Bodybuilders e, em 1998, apresenta uma de suas obras mais emblemáticas: Sumaré, na estação de mesmo nome do metrô da cidade de São Paulo. Na primeira década do novo milênio, Alex Flemming explora sua própria ideia de autorrepresentação, sem deixar de ponderar sobre os acontecimentos políticos mundiais. É neste momento que surgem obras da série Flying Carpets e Identidade Plástica, ambas de 2004. Lápides (2011) comenta sobre a morte, relacionando-a com a tecnologia. Prolífico e atuante, sua produção se estende até os dias de hoje e para além dos exemplos aqui apontados. Apocalipse (2015), Biblioteca (2016) e Anacondas (2017) atualizam a temática do artista que não se furta às discussões referentes ao corpo, à política, vida e morte.

${ }^{3}$ Oliveira (2016) evidencia a tríade vida/corpo/morte nos trabalhos de Flemming, quando ele busca a solução dos conflitos estéticos presentes em sua obra de maneira espiral, ou seja, pelo diálogo capaz de entender o corpo não somente pelo sofrimento, mas enfatizando suas antíteses e suas capacidades de ausência, de presença, de finitude e de inexorabilidade.

${ }^{4}$ Outra tecnologia utilizada é a da impressão em vidro que aparece primeiramente em Sumaré (1998).

${ }^{5}$ A obra se comunica com o escrito de Georgien (Fig. 2). 


\section{Referências}

AGUALUSA, José Eduardo. Um estranho em Goa. 2a. ed. Rio de Janeiro: Gryphus, 2010.

BALEIRO, Zeca. Bandeira (gravada por Zeca Baleiro em Por onde andará Stephen Fry? MZA Music, Rio de Janeiro, 1997. Disponível em https://www.youtube. com/watch?v=Jcxt7dtFnNw. Acesso em 25/9/2019.

BARBOSA, Ana Mae. A inquietante corporeidade de Alex Flemming. InBARBOSA, Ana Mae (Org.). Alex Flemming. São Paulo: EDUSP, 2002.

BHABA, Homi K. O local da cultura. Tradução de Myriam Ávila, Eliana Lourenço de Lima Reis e Gláucia Renate Gonçalves. 2. ed. Belo Horizonte: Editora UFMG, 2019.

BÍBLIA, Antigo Testamento. Êxodo. In BÍBLIA. Português. Bíblia sagrada: Almeida revista e corrigida. Tradução de João Ferreira de Almeida. Rio de Janeiro: Sociedade Bíblica do Brasil, 1995.

CANTON, Katia. Alex Flemming: uma poética. São Paulo: Metalivros, 2002.

CARLOS, Erasmo; CARLOS, Roberto. Se você pensa (gravada por Roberto Carlos. em $O$ inimitável. CBS, Rio de Janeiro, 1968. Disponível em https://www.youtube.com/watch?v=us137xMGucU. Acesso em 25/4/2019.
COURTINE, Jean-Jacques. Os Stakhanovistas do narcisismo: Body-building e puritanismo ostentatório na cultura americana do corpo. Tradução Mariluce Moura. In SANT'ANNA, Denise Bernuzzi de (Org.). Políticas do corpo: Elementos para uma história das práticas corporais. 2. ed. São Paulo: Estação Liberdade, 2005, p. 81114.

FLEMMING, Alex. De corpo e alma. Belo Horizonte: Fundação Clóvis Salgado, 2018.

FOUCAULT, Michel. Vigiar e punir: nascimento da prisão. Tradução de Raquel Ramalhete. 42. ed. Petrópolis: Vozes, 2014.

FOUCAULT, Michel. O corpo utópico, as heterotopias. São Paulo: n-1 Edições, 2013.

GATTI, José. Duelo de titãs: Sandow e Schwarzenegger. In PENTEADO, Fernando Marques; GATTI, José. Masculinidades: teoria, crítica e artes. São Paulo: Estação das Letras e Cores, 2011.

LAUDANNA, Mayra. Alex Flemming. São Paulo: Martins Fontes, 2016.

LENINE; RENNÓ, Carlos. Tubi Tupi (gravada por Lenine em Na pressão. Ariola Records, São Paulo, 1999. Disponível em https://www.youtube.com/watch?v=33w5 NWmyRdw. Acesso em 26/4/2019. 
OLIVEIRA, Alecsandra Matias de. Lápides Alex Flemming. Revista Usp, São Paulo, $\mathrm{n}$. 108, p. 116-126, mar. 2016.

ROSA, Samuel; ZANETTI, Lelo; AMARAL, Chico. Te ver (gravada pro Skank em Calango. Chaos, São Paulo, 1994. Disponível em https://www.youtube.com/watch?v= NK88geNsUmQ. Acesso em 24/4/2019.

SANDOVAL, Jota; CARVALHINHO. Quem sabe, sabe (gravada por Joel de Almeida e Zezinho em 78 RPM Odeon, São Bernardo do Campo, 1956. Disponível em https:// www.youtube.com/watch?v=Z_VQKWGegj M. Acesso em 26/4/2019.

VILLAÇA, Nízia. De tabu a totem: bundas. In VILLAÇA, Nízia. Em Pauta: corpo, globalização e novas tecnologias. Rio de Janeiro: Mauad, 1999.

VILLAÇA, Nízia; GOÉS, Fred. Em nome do corpo. 2. ed. São Paulo: Estação das Letras e Cores Editora Ltda., 2014. 